\title{
KAJIAN TENTANG PERSAMAAN DIFERENSIAL PARSIAL KABUR
}

\author{
ELVATHNA SYAFWAN \\ Program Studi Pasca Sarjana Matematika, \\ Fakultas Matematika dan Ilmu Pengetahuan Alam, Universitas Andalas, \\ Kampus UNAND Limau Manis Padang, Indonesia, \\ email : elvathna_sy87@yahoo.co.id
}

\begin{abstract}
Abstrak. Pada artikel ini dikaji persamaan diferensial parsial kabur serta eksistensi solusinya. Solusi yang dikaji adalah solusi Buckley-Feuring (solusi BF).

Kata Kunci: Persamaan Diferensial Parsial Kabur, Solusi Buckley-Feuring
\end{abstract}

\section{Pendahuluan}

Himpunan tegas (crisp set) adalah himpunan yang terdefinisi secara tegas, dalam arti bahwa untuk setiap elemen dalam semestanya selalu dapat ditentukan secara tegas, apakah elemen tersebut merupakan anggota dari himpunan itu atau tidak. Namun pada kenyataannya, tidak semua himpunan yang dijumpai dalam kehidupan sehari-hari terdefinisi secara tegas. Himpunan tersebut dikenal dengan himpunan kabur (fuzzy set). Teori tentang himpunan kabur pertama kali diperkenalkan oleh Profesor Lotfi A. Zadeh, seorang ilmuwan Amerika Serikat berkebangsaan Iran, dari Universitas California di Barkeley, melalui tulisannya "Fuzzy Sets" pada tahun 1965 [7]. Hal ini kemudian menginspirasi banyak peneliti lain untuk melakukan penelitian lebih lanjut, baik terkait dengan teori kabur maupun aplikasinya pada bidang ilmu yang lain. Teori maupun aplikasi himpunan kabur ini berkembang sa-ngat pesat.

Dalam matematika, persamaan diferensial parsial memegang peranan penting dalam mendeskripsikan suatu keadaan fisis, dimana besaran-besaran yang terlibat di dalamnya berubah terhadap ruang dan waktu. James J. Buckley dan Thomas Feuring [1] pada tahun 1998 memperkenalkan persamaan diferensial parsial yang di-fuzzy-fikasikan.

Pada artikel ini, akan dikaji persamaan diferensial parsial kabur serta eksistensi solusinya. Dalam hal ini, solusi persamaan diferensial parsial kabur yang dikaji adalah solusi yang diformulasi oleh Buckley-Feuring (dikenal sebagai solusi BF)[2].

\section{Persamaan Diferensial Parsial Kabur}

Misalkan $I_{1}=\left[0, M_{1}\right]$ dan $I_{2}=\left[0, M_{2}\right]$, untuk $M_{1}, M_{2}>0 . F(x, y, \mathbf{k})$ suatu fungsi kontinu di $(x, y) \in I_{1} \times I_{2}$ dan $\mathbf{k}=\left(k_{1}, \cdots, k_{n}\right)$, dengan $k_{i} \in J_{i} \subset \mathbb{R}, 1 \leq$ $i \leq n$. Operator $\varphi\left(D_{x}, D_{y}\right)$ merupakan suatu fungsi polinomial dalam $D_{x}$ dan $D_{y}$, dengan koefisien konstanta, dimana $D_{x}$ dan $D_{y}$ masing-masing menyatakan operator diferensial parsial terhadap $x$ dan $y$. Misalkan juga $U(x, y)$ adalah suatu fungsi 
kontinu yang memiliki turunan parsial yang kontinu terhadap $x$ dan $y$, dengan $(x, y) \in I_{1} \times I_{2}$. Bentuk umum persamaan diferensial parsial adalah

$$
\varphi\left(D_{x}, D_{y}\right) U(x, y)=F(x, y, \mathbf{k})
$$

dengan syarat batas tertentu. Syarat batas ini dapat muncul dalam bentuk yang bervariasi, seperti

$$
\begin{gathered}
U(0, y)=c_{1}, U(x, 0)=c_{2}, U\left(M_{1}, y\right)=c_{3}, \cdots \\
U(0, y)=g_{1}\left(y ; c_{4}\right), U(x, 0)=f_{1}\left(x ; c_{5}\right), \cdots \\
U_{x}(x, 0)=f_{2}\left(x ; c_{6}\right), U_{y}(0, y)=g_{2}\left(y ; c_{7}, c_{8}\right), \cdots
\end{gathered}
$$

Syarat batas untuk persamaan (2.1) bergantung pada konstanta-konstanta $c_{1}, \cdots, c_{m}$ dengan $c_{i} \in L_{i}, 1 \leq i \leq m$. Misalkan $\mathbf{c}=\left(c_{1}, \cdots, c_{m}\right)$.

Solusi persamaan (2.1) sebagai berikut:

$$
U(x, y)=G(x, y, \mathbf{k}, \mathbf{c})
$$

dimana $G$ adalah fungsi kontinu dengan $(x, y) \in I_{1} \times I_{2}, \mathbf{k} \in J=\Pi J_{i}, 1 \leq i \leq n$ dan $\mathbf{c} \in L=\Pi L_{i}, 1 \leq i \leq m, L_{i} \subset \mathbb{R}$.

Konstanta $k_{i}$ dan $c_{i}$ tidak diketahui secara pasti sehingga akan ada ketidakpastian pada nilai-nilainya. Nilai yang tidak pasti ini akan dimodelkan menggunakan bilangan kabur. Akan diganti bilangan kabur segitiga $\bar{K}_{i}$ untuk $k_{i}$, dengan $\bar{K}_{i} \subset J_{i}$, $1 \leq i \leq n$ dan bilangan kabur segitiga $\bar{C}_{i}$ untuk $c_{i}$, dengan $\bar{C}_{i} \subset L_{i}, 1 \leq i \leq m$. Pada artikel ini, hanya digunakan bilangan kabur segitiga karena bentuk fungsi keanggotaan segitiga lebih sederhana dan telah memenuhi syarat keanggotaan bilangan kabur.

Jika persamaan (2.1) di-fuzzy-fikasikan, maka diperoleh persamaan diferensial parsial kabur. Dengan menggunakan prinsip perluasan, $\bar{F}$ dapat dihitung dari $F$, dimana $\bar{F}(x, y, \overline{\mathbf{K}})$ mempunyai $\overline{\mathbf{K}}=\left(\bar{K}_{1}, \cdots, \bar{K}_{n}\right)$ untuk $\bar{K}_{i}$ suatu bilangan kabur segitiga, $1 \leq i \leq n$. Selanjutnya, fungsi $U$ menjadi $\bar{U}$ dimana $\bar{U}$ memetakan $I_{1} \times I_{2}$ ke dalam bilangan-bilangan kabur. Artinya, $\bar{U}(x, y)=\bar{Z}$ dimana $\bar{Z}$ adalah suatu bilangan kabur. Dengan demikian, bentuk umum persamaan diferensial parsial kabur adalah

$$
\varphi\left(D_{x}, D_{y}\right) \bar{U}(x, y)=\bar{F}(x, y, \bar{K})
$$

dengan syarat batas tertentu. Syarat batas untuk persamaan (2.4) :

$$
\begin{gathered}
\bar{U}(0, y)=\bar{C}_{1}, \bar{U}(x, 0)=\bar{C}_{2}, \bar{U}\left(M_{1}, y\right)=\bar{C}_{3}, \cdots \\
\bar{U}(0, y)=\bar{g}_{1}\left(y ; \bar{C}_{4}\right), \bar{U}(x, 0)=\bar{f}_{1}\left(x ; \bar{C}_{5}\right), \cdots, \\
\bar{U}_{x}(x, 0)=\bar{f}_{2}\left(x ; \bar{C}_{6}\right), \bar{U}_{y}(0, y)=\bar{g}_{2}\left(y ; \bar{C}_{7}, \bar{C}_{8}\right), \cdots
\end{gathered}
$$

Dalam hal ini, $\bar{g}_{i}$ dan $\bar{f}_{i}$ menggunakan prinsip perluasan dari $g_{i}$ dan $f_{i}$. Misalkan $\overline{\mathbf{C}}=\left(\bar{C}_{1}, \cdots, \bar{C}_{m}\right)$ dengan $\bar{C}_{i}$ adalah bilangan kabur segitiga, $1 \leq i \leq m$.

Selanjutnya, fungsi $G$ pada persamaan (2.3) di-fuzzy-fikasikan. Misalkan $\bar{Y}(x, y)=\bar{G}(x, y, \overline{\mathbf{K}}, \overline{\mathbf{C}})$. Kemudian misalkan $\bar{K}[\alpha]=\Pi \bar{K}_{i}[\alpha]$, dan $\bar{C}[\alpha]=\Pi \bar{C}_{i}[\alpha]$. 


\section{Solusi Buckley-Feuring}

Misalkan untuk setiap $\alpha \in[0,1]$,

$$
\begin{aligned}
\bar{Y}(x, y)[\alpha] & =\left[y_{1}(x, y, \alpha), y_{2}(x, y, \alpha)\right], \\
\bar{F}(x, y, \bar{K})[\alpha] & =\left[F_{1}(x, y, \alpha), F_{2}(x, y, \alpha)\right],
\end{aligned}
$$

dengan

$$
\begin{aligned}
& y_{1}(x, y, \alpha)=\min \{G(x, y, \mathbf{k}, \mathbf{c}) \mid \mathbf{k} \in \bar{K}[\alpha], \mathbf{c} \in \bar{C}[\alpha]\}, \\
& y_{2}(x, y, \alpha)=\max \{G(x, y, \mathbf{k}, \mathbf{c}) \mid \mathbf{k} \in \bar{K}[\alpha], \mathbf{c} \in \bar{C}[\alpha]\},
\end{aligned}
$$

dan

$$
\begin{aligned}
& F_{1}(x, y, \alpha)=\min \{F(x, y, \mathbf{k}) \mid \mathbf{k} \in \bar{K}[\alpha]\} \\
& F_{2}(x, y, \alpha)=\max \{F(x, y, \mathbf{k}) \mid \mathbf{k} \in \bar{K}[\alpha]\}
\end{aligned}
$$

untuk setiap $x, y$.

Asumsikan bahwa $y_{i}(x, y, \alpha)$ memiliki turunan parsial yang kontinu sehingga $\varphi\left(D_{x}, D_{y}\right) y_{i}(x, y, \alpha)$ kontinu untuk setiap $(x, y) \in I_{1} \times I_{2}, \alpha, i=1,2$. Definisikan

$$
\Gamma(x, y, \alpha)=\left[\varphi\left(D_{x}, D_{y}\right) y_{1}(x, y, \alpha), \varphi\left(D_{x}, D_{y}\right) y_{2}(x, y, \alpha)\right]
$$

untuk setiap $(x, y) \in I_{1} \times I_{2}$, dan setiap $\alpha$. Jika untuk setiap $(x, y)$ di $I_{1} \times I_{2}$, $\Gamma(x, y, \alpha)$ mendefinisikan $\alpha$-cut dari suatu bilangan kabur, maka dapat dikatakan bahwa $\bar{Y}(x, y)$ terdiferensial dan ditulis

$$
\varphi\left(D_{x}, D_{y}\right) \bar{Y}(x, y)[\alpha]=\Gamma(x, y, \alpha)
$$

untuk setiap $\alpha$.

Syarat cukup bagi $\Gamma(x, y, \alpha)$ agar merupakan suatu $\alpha$-cut dari bilangan kabur adalah [5]:

(i) $\varphi\left(D_{x}, D_{y}\right) y_{1}(x, y, \alpha)$ merupakan fungsi naik dari $\alpha$ untuk setiap $(x, y) \in I_{1} \times I_{2}$,

(ii) $\varphi\left(D_{x}, D_{y}\right) y_{2}(x, y, \alpha)$ merupakan fungsi turun dari $\alpha$ untuk setiap $(x, y) \in I_{1} \times$ $I_{2}$,

(iii) $\varphi\left(D_{x}, D_{y}\right) y_{1}(x, y, 1) \leq \varphi\left(D_{x}, D_{y}\right) y_{2}(x, y, 1)$ untuk setiap $(x, y) \in I_{1} \times I_{2}$.

Telah diasumsikan bahwa $y_{i}(x, y, \alpha)$ memiliki turunan parsial yang kontinu sehingga $\varphi\left(D_{x}, D_{y}\right) y_{i}(x, y, \alpha)$ kontinu pada $I_{1} \times I_{2} \times[0,1], i=1,2$. Dengan demikian, jika syarat (i)-(iii) di atas terpenuhi, maka $\Gamma(x, y, \alpha)$ suatu $\alpha$-cut dari bilangan kabur. Jelas $\bar{Y}(x, y)$ terdiferensial.

Agar $\bar{Y}(x, y)$ menjadi suatu solusi dari persamaaan diferensial parsial kabur, maka haruslah :

(a) $\bar{Y}(x, y)$ terdiferensial,

(b) Persamaan (2.4) terpenuhi untuk $\bar{U}(x, y)=\bar{Y}(x, y)$,

(c) $\bar{Y}(x, y)$ memenuhi syarat batas.

Karena syarat batas tidak dinyatakan secara khusus, maka hanya diperiksa apakah persamaan (2.4) terpenuhi. 
Berikut diberikan definisi solusi BF tanpa syarat batas.

Definisi 3.1. [1] $\bar{Y}(x, y)$ dikatakan solusi BF tanpa syarat batas jika $\bar{Y}(x, y)$ terdiferensial dan

$$
\varphi\left(D_{x}, D_{y}\right) \bar{Y}(x, y)=\bar{F}(x, y, \overline{\boldsymbol{K}}) .
$$

atau persamaan berikut terpenuhi:

$$
\begin{aligned}
& \varphi\left(D_{x}, D_{y}\right) y_{1}(x, y, \alpha)=F_{1}(x, y, \alpha), \\
& \varphi\left(D_{x}, D_{y}\right) y_{2}(x, y, \alpha)=F_{2}(x, y, \alpha),
\end{aligned}
$$

untuk setiap $(x, y) \in I_{1} \times I_{2}$ dan setiap $\alpha$.

Jika $\bar{Y}(x, y)$ merupakan solusi BF dan memenuhi syarat batas, maka $\bar{Y}(x, y)$ dikatakan solusi BF yang memenuhi syarat batas.

\section{Syarat Cukup Eksistensi Solusi Buckley-Feuring}

Pada artikel ini akan diberikan syarat cukup agar solusi BF ada. Karena ada banyak kemungkinan syarat batas, maka syarat batas dalam pembahasan berikut diabaikan. Jadi, dalam hal ini konstanta $c_{i}, 1 \leq i \leq m$ tidak dilibatkan. De-ngan demikian persamaan $(2.3)$ menjadi $U(x, y)=\bar{G}(x, y, \mathbf{k})$, sehingga $\bar{Y}(x, y)=\bar{G}(x, y, \overline{\mathbf{K}})$.

Teorema 4.1. [1] Asumsikan $\bar{Y}(x, y)$ terdiferensial.

(a) Jika untuk setiap $i \in\{1, \cdots, n\}, G(x, y, \boldsymbol{k})$ dan $F(x, y, \boldsymbol{k})$ keduanya fungsi naik (atau keduanya fungsi turun) pada $k_{i}$, untuk $(x, y) \in I_{1} \times I_{2}$ dan $\boldsymbol{k} \in J$, maka $\bar{Y}(x, y)$ adalah solusi BF.

(b) Jika terdapat $i \in\{1, \cdots, n\}$ sehingga untuk variabel $k_{i}, G(x, y, \boldsymbol{k})$ merupakan fungsi naik sejati dan $F(x, y, \boldsymbol{k})$ merupakan fungsi turun sejati (atau $G(x, y, \boldsymbol{k})$ merupakan fungsi turun sejati dan $F(x, y, \boldsymbol{k})$ merupakan fungsi naik sejati), untuk $(x, y) \in I_{1} \times I_{2}$ dan $\boldsymbol{k} \in J$, maka $\bar{Y}(x, y)$ bukan solusi $B F$.

\section{Bukti.}

(a) Untuk penyederhanaan, asumsikan $n=2$. Misalkan $G(x, y, \mathbf{k})$ adalah fungsi naik pada $k_{1}, F(x, y, \mathbf{k})$ fungsi naik pada $k_{1}, G(x, y, \mathbf{k})$ adalah fungsi turun pada $k_{2}$ dan $F(x, y, \mathbf{k})$ fungsi turun pada $k_{2}$. Maka dari persamaan (3.1)-(3.4) diperoleh

$$
\begin{aligned}
y_{1}(x, y, \alpha) & =\min \left\{G(x, y, \mathbf{k}) \mid \mathbf{k} \in \bar{K}_{1}[\alpha] \times \bar{K}_{2}[\alpha]\right\} \\
& =G\left(x, y, k_{11}(\alpha), k_{22}(\alpha)\right), \\
y_{2}(x, y, \alpha) & =\max \left\{G(x, y, \mathbf{k}) \mid \mathbf{k} \in \bar{K}_{1}[\alpha] \times \bar{K}_{2}[\alpha]\right\} \\
& =G\left(x, y, k_{12}(\alpha), k_{21}(\alpha)\right), \\
F_{1}(x, y, \alpha) & =\min \left\{F(x, y, \mathbf{k}) \mid \mathbf{k} \in \bar{K}_{1}[\alpha] \times \bar{K}_{2}[\alpha]\right\} \\
& =F\left(x, y, k_{11}(\alpha), k_{22}(\alpha)\right), \\
F_{2}(x, y, \alpha) & =\max \left\{F(x, y, \mathbf{k}) \mid \mathbf{k} \in \bar{K}_{1}[\alpha] \times \bar{K}_{2}[\alpha]\right\} \\
& =F\left(x, y, k_{12}(\alpha), k_{21}(\alpha)\right),
\end{aligned}
$$


untuk setiap $\alpha$ dimana $\bar{K}_{1}[\alpha]=\left[k_{11}(\alpha), k_{12}(\alpha)\right]$ dan $\bar{K}_{2}[\alpha]=\left[k_{21}(\alpha), k_{22}(\alpha)\right]$.

Selanjutnya $G$ merupakan solusi persamaan diferensial parsial, artinya

$$
\varphi\left(D_{x}, D_{y}\right) G\left(x, y, k_{1}, k_{2}\right)=F\left(x, y, k_{1}, k_{2}\right)
$$

untuk setiap $(x, y) \in I_{1} \times I_{2}, k_{1} \in J_{1}$ dan $k_{2} \in J_{2}$. Tetapi $k_{1 j}(\alpha) \in J_{1}$ dan $k_{2 j}(\alpha) \in J_{2}$ untuk setiap $\alpha, j=1,2$, sehingga

$$
\begin{aligned}
\varphi\left(D_{x}, D_{y}\right) y_{1}(x, y, \alpha) & =\varphi\left(D_{x}, D_{y}\right) G\left(x, y, k_{11}(\alpha), k_{22}(\alpha)\right) \\
& =F\left(x, y, k_{11}(\alpha), k_{22}(\alpha)\right) \\
& =F_{1}(x, y, \alpha) \\
\varphi\left(D_{x}, D_{y}\right) y_{2}(x, y, \alpha) & =\varphi\left(D_{x}, D_{y}\right) G\left(x, y, k_{12}(\alpha), k_{21}(\alpha)\right) \\
& =F\left(x, y, k_{12}(\alpha), k_{21}(\alpha)\right) \\
& =F_{2}(x, y, \alpha),
\end{aligned}
$$

untuk setiap $(x, y) \in I_{1} \times I_{2}$ dan setiap $\alpha$. Dengan demikian persamaan (3.8) dan (3.9) terpenuhi, sehingga $\bar{Y}(x, y)$ adalah solusi BF.

(b) Misalkan $n=2$ dan $G(x, y, k)$ adalah fungsi naik sejati pada $k_{1}, F(x, y, k)$ adalah fungsi turun sejati pada $k_{1}$, tetapi kedua fungsi $G$ dan $F$ merupakan fungsi turun sejati pada $k_{2}$. Maka persamaan (4.1) dan (4.2) tetap berlaku tetapi persamaan (4.3) dan (4.4) menjadi

$$
\begin{aligned}
F_{1}(x, y, \alpha) & =\min \left\{F(x, y, \mathbf{k}) \mid \mathbf{k} \in \bar{K}_{1}[\alpha] \times \bar{K}_{2}[\alpha]\right\} \\
& =F\left(x, y, k_{12}(\alpha), k_{22}(\alpha)\right) \\
F_{2}(x, y, \alpha) & =\max \left\{F(x, y, \mathbf{k}) \mid \mathbf{k} \in \bar{K}_{1}[\alpha] \times \bar{K}_{2}[\alpha]\right\} \\
& =F\left(x, y, k_{11}(\alpha), k_{21}(\alpha)\right),
\end{aligned}
$$

untuk setiap $\alpha$. Dengan demikian persamaan (3.8) dan (3.9) tidak terpenuhi. Jadi, $\bar{Y}(x, y)$ bukan solusi BF.

Akibat 4.2. [1] Asumsikan $\bar{Y}(x, y)$ terdiferensial.

(a) $\bar{Y}(x, y)$ adalah solusi BF jika

$$
\frac{\partial G}{\partial k_{i}} \frac{\partial F}{\partial k_{i}}>0
$$

untuk $i=1,2, \cdots, n,(x, y) \in I_{1} \times I_{2}$ dan $\boldsymbol{k} \in J$.

(b) Jika

$$
\frac{\partial G}{\partial k_{i}} \frac{\partial F}{\partial k_{i}}<0
$$

untuk suatu $i,(x, y) \in I_{1} \times I_{2}, \boldsymbol{k} \in J$, maka $\bar{Y}(x, y)$ bukan solusi $B F$. 


\section{Kesimpulan}

Pada artikel ini telah dijelaskan tentang konsep persamaan diferensial parsial kabur yang merupakan pengembangan dari konsep persamaan diferensial parsial dan teori fuzzy. Dalam hal ini, bentuk umum persamaan diferensial parsial kabur diberikan oleh

$$
\varphi\left(D_{x}, D_{y}\right) \bar{U}(x, y)=\bar{F}(x, y, \bar{K})
$$

Misalkan solusi dari persamaan (5.1) diberikan oleh $\bar{Y}(x, y)=\bar{G}(x, y, \bar{K}, \bar{C})$.

Syarat cukup bagi eksistensi solusi Buckley-Feuring (solusi BF) dari persamaan diferensial parsial kabur (5.1) adalah sebagai berikut. Asumsikan $\bar{Y}(x, y)$ terdiferensial. Maka

(a) Jika untuk setiap $i \in\{1, \cdots, n\}, G(x, y, \mathbf{k})$ dan $F(x, y, \mathbf{k})$ keduanya fungsi naik (atau keduanya fungsi turun) pada $k_{i}$, untuk $(x, y) \in I_{1} \times I_{2}$ dan $\mathbf{k} \in J$, maka $\bar{Y}(x, y)$ adalah solusi BF.

(b) Jika terdapat $i \in\{1, \cdots, n\}$ sehingga untuk variabel $k_{i}, G(x, y, \mathbf{k})$ merupakan fungsi naik sejati dan $F(x, y, \mathbf{k})$ merupakan fungsi turun sejati (atau $G(x, y, \mathbf{k})$ merupakan fungsi turun sejati dan $F(x, y, \mathbf{k})$ merupakan fungsi naik sejati), untuk $(x, y) \in I_{1} \times I_{2}$ dan $\mathbf{k} \in J$, maka $\bar{Y}(x, y)$ bukan solusi BF.

Akibatnya, apabila diasumsikan $\bar{Y}(x, y)$ terdiferensial, maka

(a) $\bar{Y}(x, y)$ adalah solusi BF jika

$$
\frac{\partial G}{\partial k_{i}} \frac{\partial F}{\partial k_{i}}>0
$$

untuk $i=1,2, \cdots, n,(x, y) \in I_{1} \times I_{2}$ dan $\mathbf{k} \in J$.

(b) Jika

$$
\frac{\partial G}{\partial k_{i}} \frac{\partial F}{\partial k_{i}}<0
$$

untuk suatu $i,(x, y) \in I_{1} \times I_{2}, \mathbf{k} \in J$, maka $\bar{Y}(x, y)$ bukan solusi BF.

\section{Saran}

Kajian tentang persamaan diferensial parsial kabur dan eksistensi solusinya dapat diperluas untuk solusi lainnya, seperti solusi Seikkala, solusi Puri-Ralescu, dan solusi Kandel-Friedman-Ming [2].

\section{Daftar Pustaka}

[1] Buckley, J, J dan Feuring, T. 2000. Introduction to Fuzzy Partial Differential Equations. Fuzzy Sets and Systems. 105: $241-248$.

[2] Buckley, J, J dan Feuring, T. 1997. Fuzzy Differential Equation. Fuzzy Sets and Systems. 110: $43-54$.

[3] Buckley, J, J dan Qu, Y. 1990. On Using $\alpha$-cuts to Evaluate Fuzzy Functions. Fuzzy Sets and Systems. 138: 309 - 312.

[4] Dubois, D dan Prahe, H. 1998. Operation on Fuzzy Numbers. System Sci. 9: $613-628$. 
Kajian Tentang Persamaan Diferensial Parsial Kabur 15

[5] Goetschel, R dan Voxman, W. 1986. Elementary Fuzzy Calculus. Fuzzy Sets and Systems. 18: $31-43$.

[6] Kwang, L, H. 2005. First Course on Fuzzy Theory and Applications. Springer. Berlin.

[7] Zadeh, L, A. 1965. Information and Control. Fuzzy Sets and Systems. 8: $338-$ 353. 